\title{
EBW TECHNOLOGY APPLIED ON THE ICRF ANTENNA COMPONENT
}

\author{
Q.X. Yang ${ }^{\mathrm{a}}$, Y.T. Song ${ }^{\mathrm{a}}$, Y.S. Wang ${ }^{\mathrm{a}}$, Y. Wan ${ }^{\mathrm{a}}, \mathrm{H}$, Funfgelder $^{\mathrm{b}}$, T. Vierle ${ }^{\mathrm{b}}$, L.N. Liu ${ }^{\mathrm{b}}$, F.Zeus $^{\mathrm{b}}$ \\ a. Institute of Plasma Physics, Chinese Academy of Science, China, 230031 \\ b. Max-Planck-Institute of Plasma Physics, Garching, Germany, D-85748 \\ yangqx@ipp.ac.cn
}

\begin{abstract}
Central conductor is one of the key components of ICRF antenna, it is usually formed by welding due to the complex structure. High level of welding seam quality and small deformation are very important to central conductor. Electron beam welding (EBW) have been chosen to be used. In order to meet EBW requirements and reduce the risk, Complex and high level of the accuracy welding fixture have been designed for central conductor EBW. Some samples were manufactured to do test and examination for EBW welding qualification before central conductor welding. Based on the welding parameters, thermal analysis using FEM for the welding seam have been carried out. One mock up of central conductor have been manufactured to do EB welding for proving welding parameters, In addition to some post welding process were employed after one central conductor EB welding, Results of examination and inspection of one central conductor using EBW are presented in this paper.
\end{abstract}

Keywords-ICRF antenna, central conductor, EBW, FEM, Mock up

\section{INTRODUCTION}

In the fusion machines, ohmic heating is employed for the initial heating of plasma, with the temperature increase, the capacity of ohmic heating is limited ${ }^{[1]}$. Therefore it is necessary to provided auxiliary means of heating if the temperature needed for a reactor. ICRF (Ion Cyclotron Ranges of Heating) as one of the heating resources with tens of $\mathrm{MHz}$ has long development history and it has been applied to RF heating system of the magnetically confined fusion devices such as tokamak and stellerator. An upgraded ICRF antenna for Max-Planck-Institute of Plasma Physics (IPP), Garching, Germany, have been designed and manufactured cooperating with the Institute of Plasma Physics, Chinese Academy of Sciences (ASIPP). The new ICRF antenna system is composed of, high power supply system, RF transmitter, transmission lines, matching system, Vacuum feedthrough, antenna, and et al. Regarding to the antenna, central conductor is one of the important components, which has the function of coupling power to plasma during operation. Since high tolerance and welding quality requirements for central conductor, electron beam welding is employed. Compared to TIG welding, it has the advantages of very low heat input to the weld, resulting in low distortion in components, as a consequence it is being increasingly used in industrial manufacturing and is of growing importance in industry ${ }^{[2]}$.

\section{MOTIVATION OF EBW APPLIED ON THE CENTRAL CONDUCTOR}

For the upgraded ICRF antenna of ASDEX tokamak, three central conductors have been designed and manufactured to assemble in a array on the return conductor. Layout of central conductors on the antenna is shown in Fig.1. As shown in Fig.1, Central conductor has complex structure with several winding, if it is formed by manufacturing by one thickness plate, the cost is very high and time will be much long, the welding is employed for central conductor forming. As the central conductor is required with low permeability $(\mu \leqslant 1.05)$ and high precision geometry, the electrical beam welding (EBW) method is employed. Comparing to TIG welding, the EBW has the following advantages ${ }^{[3-5]}$ :

1. Electron beam penetrating ability, weld aspect ratio

2. Welding speed, small heat affected zone and small welding deformation

3. Good welding quality for welding in the vacuum environment

4. Easily welding in different zone even with long distance from the beam gun

5. Easily control the electron beam during welding.

The advantages of EBW method listed above, are indicated that EBW is much better than TIG welding .
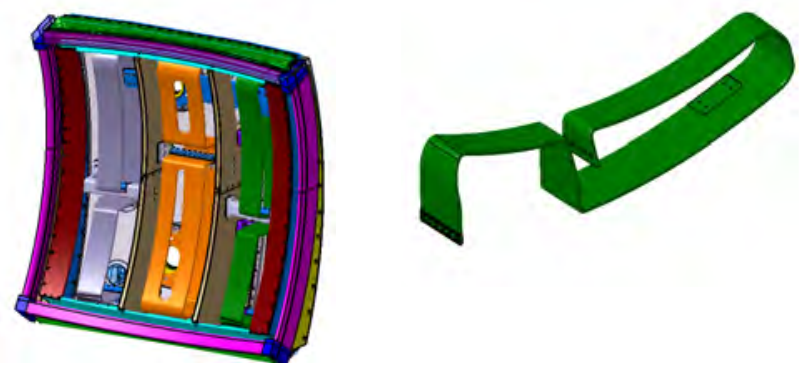

Fig.1. Central conductor assembly (left) and Structure of central conductor (right)

\section{EBW QUALIFICATION FOR CENTRAL CONDUCTOR}

Before the product of central conductor starts welding, some small workpieces were fabricated to do EBW for qualification, obtaining satisfactory welding parameters (welding speed, electron beam power, beam current, 
accelerating voltage, etc.). Since the thickness of central conductor being $10 \mathrm{~mm}$ and linear butt weld, two standard workpieces with $10 \mathrm{~mm}$ thickness and same weld joint type were fabricated and welded, are shown in Fig.2. Based on EB welding requirements, before welding surface of the welding joint must be cleaned to remove the contaminations, gap between backing plate and workpiece be less than $0.1 \mathrm{~mm}$ to avoid the incompletely filled groove, in addition to no steps more than $0.05 \mathrm{~mm}$, no gaps more than $0.1 \mathrm{~mm}$ at the joint. The backing plate was employed to prevent undercut and weld spatter at both sides of the plate, material of it was chosen as the parent material SS316LN so as to the lower the permeability affecting the beam concentration.
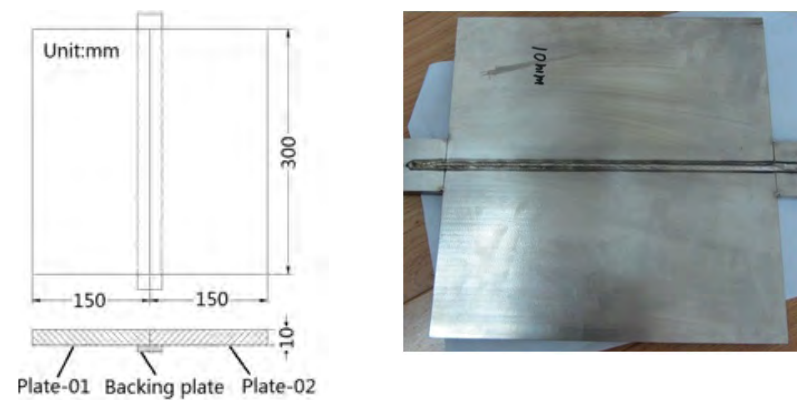

Fig.2. Workpiece dimension and post-weld weldment

With purpose of obtain valid and fittest welding parameters for antenna central conductor EB welding. Based on the welding structures of the central condcutor, several workpieces, were manufactured for EB welding trial, nondestructive and destructive test and examination have been done for welding qualification. Regarding to the nondestructive test, three action items have been done, they are permeability, Visual inspection, dye penetrant test. In addition, three action items have been carried out for destructive test, they are metallographic test, tensile test and hardness test. Some test pictures are shown in Fig.3-Fig.6.
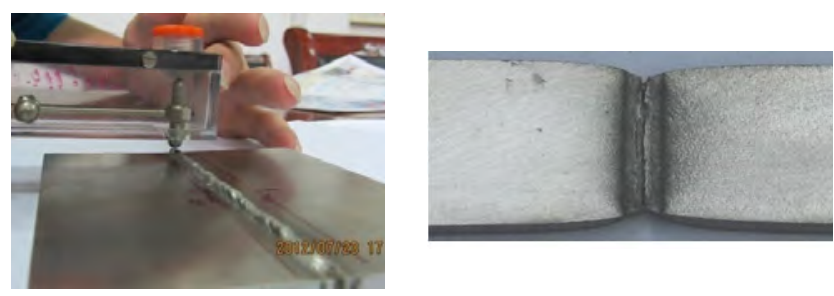

Fig.3. Permeability inspection (left ) and tensile test (right) of the weldment

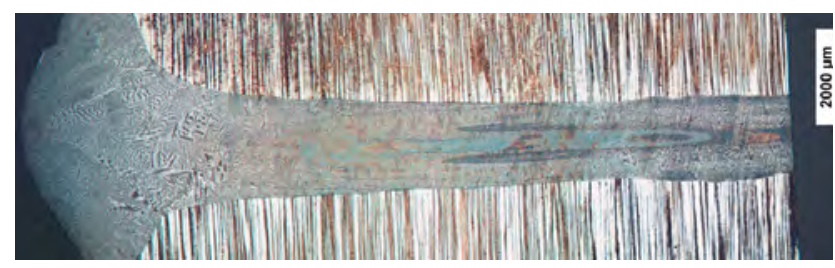

a

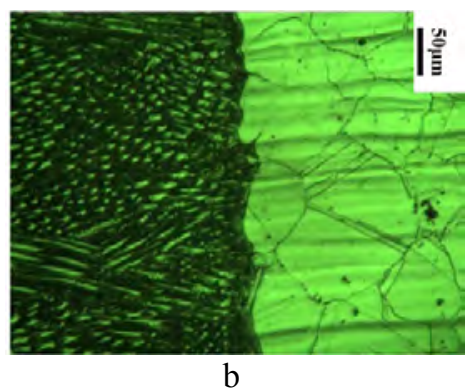

Fig.4. Macroscopic (a) and microscopic (b) examination of weldment

Based on the non-destructive test and examination results of the weldments, the permeability of all the weldments were below the 1.05. visual examination and dye penetration results are shown that no defect and imperfection were found on the welding seam. In addition to the destructive test and examination results of the weldments, the tensile stress for all the test weldments is $617 \mathrm{MPa} \leq \sigma \leq 625 \mathrm{MPa}$ almost same as that of parent material. For the metallographic test, no defect is found and heat affected zone is small on the test weldment during macroscopic examination. To furtherly verify small affected zone on the weldment, thermal analysis have been carried out by the finite element method (FEM) using welding parameters, results of temperature distribution on the weldment are shown in Fig.5. From the microscopic examination, Austenite $+\delta$ ferrite elements are found in the welding seam zone. Besides those, Vickers hardness test have been done for unaffected zone, heat affected zone (HAZ) and welding seaming zone of the test weldment. As shown in Fig.6, the hardness in the heat affected zone is the highest which more than $180 \mathrm{HV} 10$, in the unaffected zone (UZ) comes second, in the welding seam zone (WSZ) is the lowest. According to the non-destructive and destructive tests and examination for the weldments, all the results satisfy standard requirements (ISO 13919-B) .

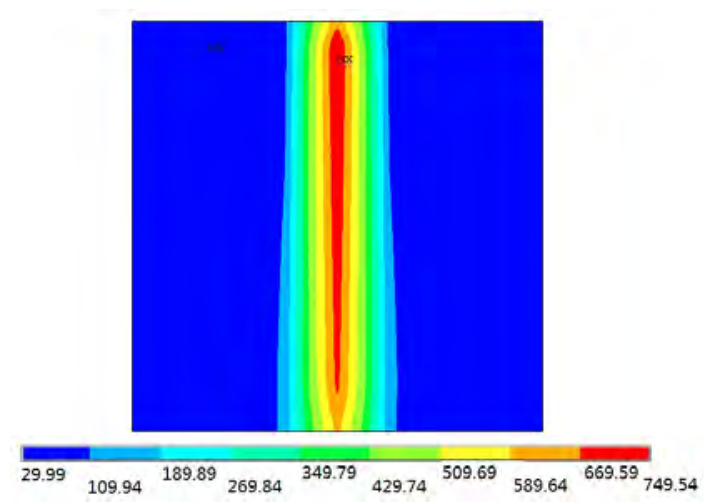

Fig.5. Temperature distribution on the weldment at time of $30 \mathrm{~s}$. 


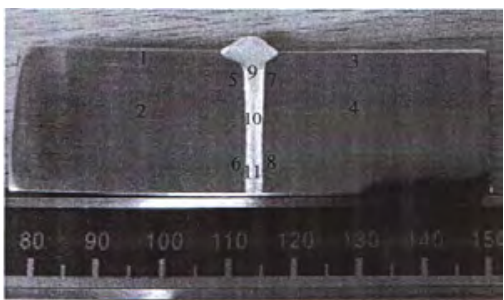

a

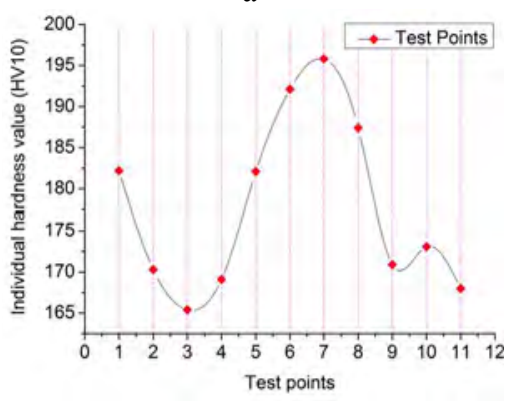

b

Fig.6. Test points position (a) and Vickers hardness test results (b)

\section{DEMONSTRATION OF THE CENTRAL CONDUCTOR MOCKUP EBW}

Although weldments as sample were used to do test and examination for welding qualification, the deformation and stable-operation welding will require to demonstrate by the mockup of central conductor. Weld quality, weld fixture feasibility, deformation, post-weld dealing can be further demonstration and reference for the real product of central conductor EB welding. Based on the structure of central conductor and EBW welding requirements, special welding fixture have been designed and fabricated. Structure of welding fixture and central conductor assembed for EB welding are shown in Fig.7. As shown in Fig.7, welding fixture mainly comprises top and bottom plates, a few fixed rods, some fasten double -screw bolts as well, the whole fixture is easily fixed and disassembled .

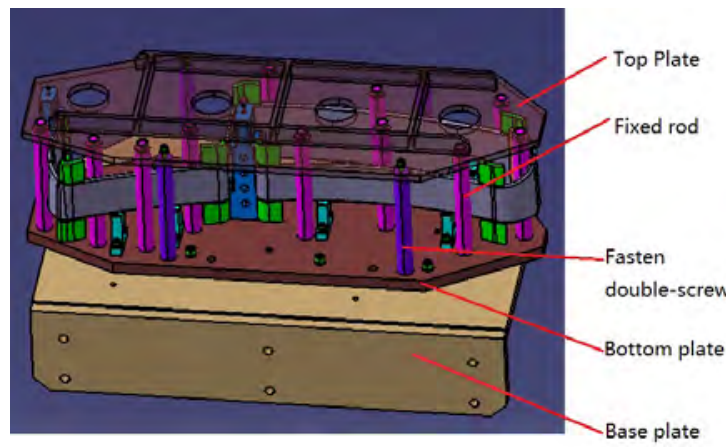

Fig.7. Structure of welding fixture for central conductor mockup welding
After central conductor EB welding, a few jobs of post welding will be done, they are included heat treatment, baking plate removal, non-destructive examination for welding seam, shape correction, polishing and final dimension measurement. To release stress from the welding process, heat treatment for the mockup of central conductor have been carried out in the vacuum furnace, backing plate removal was followed by the heat treatment. After that, inspection and examination including dye penetration, permeability examination, visual examination were done, no defect and imperfection were found, permeability of the weld seam are lower than 1.05. Although minor deformation from the EBW, shape correction was done for satisfactory figure and dimension. Since roughness of the central conductor, especial function contact surface is important, polishing was done after shape correction. The last job is dimension measurement, a mockup of central conductor and measurement through three coordinates measuring instrument are presented in Fig. 8, results of measurement for the mockup satisfy the requirements.
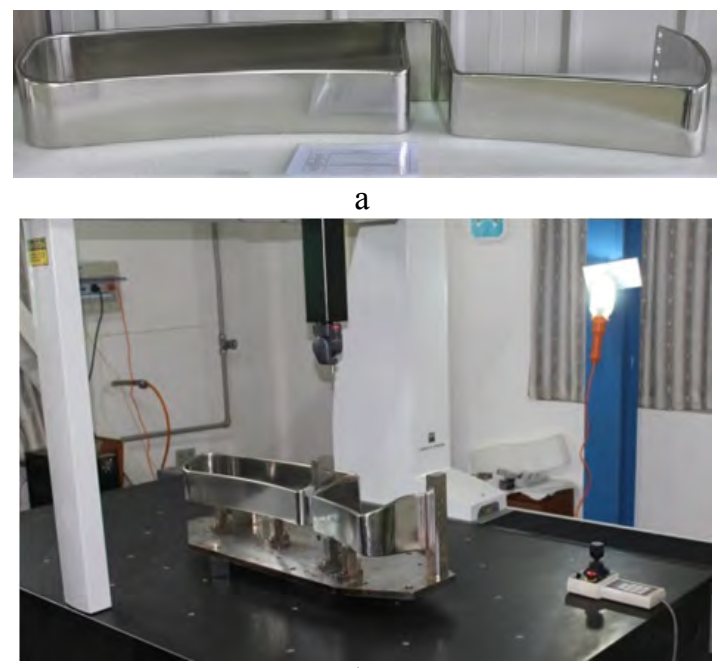

b

Fig.8. A central conductor mockup (left) and the mockup measurement (right)

\section{SUMMARY}

Based on the central conductor structure and technology requirements, EBW was employed. Before real productor of central conductor was welded, non-destructive and destructive test and examination on the weldments have been carried out for welding qualification, obtaining appropriate welding parameters, then the mockup of central conductor was done EBW using the welding parameters obtained from weldments test and examination. Postwelding jobs including non-destructive inspection, shape correction, heat treatment, polish as well as dimension measurement have been completed. Results of inspection and measurement satisfy design requirements, the welding parameters used on mockup will be employed on the productor of central conductor welding. 


\section{REFERENCE}

1. Pietro Testoni, Piergiorgio Sonato. Development of the ICRF antenna for the next step fusion reactor ITER. http://www.ansys.com/staticassets/ANSYS/staticassets/ resourcelibrary/confpaper/2004-Int-ANSYS-Conf32.PDF.

2. Piotr Lackia, ${ }^{*}$, Konrad Adamusb. Numerical simulation of the electron beam welding process. Computers and Structures, 89(2011), 977-985.

3. A. Sanderson*, C.S. Punshon, J.D. Russell. Advanced welding process for fusion reactor fabrication. Fusion Engineer and Design, 49-50(2000) 77-87.

4. Mikael Brian Olsson Robbiea,*, Niall Hamilton a, James Wood a, et al. Observations on the post-mortem investigation of electron beam welds and other microstructural features of JET Hypervapotrons. Fusion Engineering and Design, 86(2011)2394-2397.

5. Wang Zhikang, Gao Yonghua, Xu Bin. Vacuum Electric beam welding equipment and Process. Handbook [M], Atomic Energy Science Press, Beijing, 2000 . 